\title{
ANÁlisis DE COMPETITIVIDAD FRENTE AL COMERCIO EXTERIOR PARA EL MERCADO DE CACAO, MIEL NATURAL Y CEBOLLA EN HONDURAS 2006-2019
}

\author{
María Auxiliadora López* \\ Alejandro Dahir Cedillo Cerrato***
}

DOI: 10.5377 EYA.V12I2.12969

Recibido: 09/05/2021

Aceptado: 22/11/2021

\section{RESUMEN}

En la presente investigación, se estudió la competitividad de las exportaciones hondureñas de cacao, miel natural y la cebolla, para dicho análisis se calculó el índice de competitividad de las exportaciones según el enfoque de Bela Balassa, comúnmente conocido por Ventaja Comparativa Revelada (VCR); esta metodología se aplicó para comparar el monto de las exportaciones de un producto determinado de un país, respecto a las exportaciones totales enviadas al mundo y, a su vez, se comparó el resultado obtenido para otros países competidores. El estudio se realizó considerando que el objetivo principal de la investigación es explicar los principales hallazgos sobre el comportamiento de los resultados obtenidos por el índice de VCR de las exportaciones para Honduras, comparado con los socios comerciales de Centroamérica. Los resultados obtenidos mostraron que Honduras no posee VCR en las exportaciones de los productos analizados respecto a los países centroamericanos, sin embargo, el país de la región con los mejores resultados de competitividad para el mercado de la cebolla fue Guatemala. Por otro lado, Nicaragua fue el país más competitivo en las exportaciones de cacao y, E1 Salvador mostró los mejores resultados para la miel natural.

PALABRAS CLAVES: competitividad, ventaja comparativa, cebolla, cacao, miel.

JEL: F00, F11, F14

\footnotetext{
* Profesora e investigadora universitaria, Universidad Nacional Autónoma de Honduras. https://orcid.org/0000-0001-8618-8662 Correo electrónico: maria.lopez@unah.edu.hn Tegucigalpa, Honduras.

** Investigador, Universidad Nacional Autónoma de Honduras https://orcid.org/0000-0002-3570-8661 Correo electrónico: alejandro. cedillo@unah.hn Tegucigalpa, Honduras
} 


\title{
Analysis of competitiveness against foreign TRADE FOR THE MARKET FOR COCOA, NATURAL HONEY AND ONION IN HONDURAS 2006-2019
}

\author{
María Auxiliadora López* \\ Alejandro Dahir Cedillo Cerrato**
}

DOI: 10.5377/EYA.V1212.12969

Received: 09/05/2021 Accepted: 22/11/2021

\begin{abstract}
In this research, the competitiveness of Honduran exports of cocoa, natural honey and onion was studied; for this analysis, the export competitiveness index was calculated according to the Bela Balassa approach, commonly known as Revealed Comparative Advantage (VCR ); This methodology was applied to compare the amount of exports of a given product from a country with respect to total exports sent to the world and, in turn, the result obtained for other competing countries was compared. The study was carried out considering that the main objective of the research is to explain the main findings on the behavior of the results obtained by the VCR index of exports for Honduras, compared with the commercial partners of Central America. The results obtained showed that Honduras does not have VCR in the exports of the analyzed products compared to the Central American countries; However, the country in the region with the best competitiveness results for the onion market was Guatemala. On the other hand, Nicaragua was the most competitive country in cocoa exports and E1 Salvador showed the best results for natural honey.
\end{abstract}

KEYWORDS: competitiveness, comparative advantage, onion, cocoa, honey.

JEL: F00, F11, F14

\footnotetext{
* Research professor, National Autonomous University of Honduras. https://orcid.org/0000-0001-8618-8662 Email: maria.lopez@unah. edu.hn Tegucigalpa, Honduras.

** Research, National Autonomous University of Honduras, https://orcid.org/0000-0002-3570-8661 Email: alejandro.cedillo@unah.hn Tegucigalpa, Honduras.
} 


\section{INTRODUCCIÓN}

En el Comercio Internacional se requiere ser muy competitivos a la hora de producir para cubrir una demanda no solo local, sino también en el resto del mundo. Los países necesitan ser lo más productivos y competitivos para poder ser referentes en la fabricación de determinado bien o servicio. Ante esta situación, existe la necesidad de medir y analizar las ventajas y desventajas comparativas de cada uno de los países que participan en el comercio exterior y así, poder calcular el nivel de competitividad y la posición en la que se encuentran respecto a otros competidores.

La evidencia empírica revela que existen diferentes tipos de metodologías para calcular índices de competitividad. En diversos países, incluyendo la región Latinoamericana, se han desarrollado estudios orientados a medir la posición del mercado nacional frente a la competencia extranjera. En ese sentido, considerando que los tomadores de decisiones de política exterior se basan en teoría económica con una metodología estandarizada, es necesario analizar el comportamiento de las exportaciones con algún socio comercial con el que se pretenda hacer la comparación y así, determinar la ventaja comparativa de las exportaciones de cacao, miel natural y la cebolla. Cabe destacar que, según las fuentes bibliográficas consultadas, las ventajas comparativas se pueden medir a través de distintos métodos, entre ellos el índice de ventajas comparativas de las exportaciones, el cual permite calcular el nivel de competitividad en las exportaciones de productos agrícolas comparado con los demás socios en la región centroamericana.

Aunado a lo anterior, la metodología aplicada en el estudio permite comparar los resultados con cada uno de los países de Centroamérica y determinar qué país de la región posee mayor competitividad en los tres productos analizados, en ese sentido, con la aplicación de la metodología de Ventaja Comparativa Revelada (VCR), se espera lograr el objetivo de explicar los principales hallazgos en el comportamiento de los resultados del índice para Honduras sobre las exportaciones de cacao, miel natural y cebolla y, del mismo modo, determinar si posee competitividad medida a través del indicador de VCR. Finalmente, se identificarán los principales factores que influyen en los resultados de competitividad de las exportaciones respecto a los socios comerciales de la región del Mercado Común Centroamericano (MCCA) durante el período 2006-2019.

Según Krugman, Obstfeld y Melitz (2012) los países participan en el comercio internacional porque tienen diferencias y porque buscan lograr tan ansiadas economías de escala en la producción, esto significa que si cada competidor pudiera producir una canasta específica de bienes y servicios sería mucho más eficiente y competitivo en la producción y, por ende, en las exportaciones, ya que en el comercio internacional se logra producir grandes cantidades de mercancías porque se permite especializarse en productos específicos en los que se posee ventajas comparativas (p.25).

Es vista de lo anterior, es importante destacar que el principal incentivo que tienen las naciones para incursionar en el comercio exterior es el intercambio de bienes, en ese sentido, se puede interpretar que cada participante del Mercado Común Centroamericano (MCCA) posee diferencias en su estructura productiva y, por lo tanto, las ventajas comparativas de las exportaciones dependerán de la especialización en la producción de un bien en específico.

En conexión con lo anterior, según Magaña et al. (2017), con la Ventaja Comparativa Revelada se pretende que la producción doméstica sea relativamente menos costosa respecto a otros competidores, obteniendo así el mayor beneficio posible, ya que la decisión de importar o exportar dependerá de los costos relativos. Este análisis se puede aplicar al mercado de cacao, miel natural y la cebolla, ya que la estructura de la balanza 
comercial puede proveer información sobre la especialización de un país respecto a la producción de dichos productos, considerando que, al importar grandes volúmenes de una mercancía, se entiende que le resulta relativamente más caro producirla localmente, comparado con otros competidores.

De hecho, como ejemplo, Honduras presenta dificultades para satisfacer la demanda local de miel natural, lo que se traduce en altos volúmenes de importación. Según la Secretaría de Agricultura y Ganadería (SAG) (2016) en su informe sobre Análisis de Coyuntura del Cultivo de Miel de Abeja en Honduras, el consumo per cápita del gramo de miel de abeja en el país fue de alrededor de 30 gramos al año durante el período 2010-2013 y el porcentaje de dependencia de las importaciones de miel fue de alrededor del 50\%. En promedio, se consumió alrededor de 34 gramos de miel natural por persona en el país, que en su mayoría corresponde a miel importada.

Honduras se ha caracterizado por ser un país productor y exportador de productos agrícolas, entre otros. En los últimos años las exportaciones de cacao han aumentado, especialmente a partir del año 2014 ya que el monto de las exportaciones superó en un 100\% a las registradas en el año 2013, con valores de 1,155,203.58 y 559,347.86 respectivamente, con estos resultados se plantea que exista ventaja comparativa en las exportaciones de cacao aplicando el índice antes mencionado (BCH, 2019c), tal como lo plantearon Calmon et al. (2020) en su estudio sobre Especialización y competitividad: análisis de las exportaciones brasileñas de cacao en grano y productos, donde aplicaron la metodología de VCR de Balassa para cacao en grano de Brasil. Los resultados obtenidos en dicho estudio muestran al país sudamericano con una ventaja comparativa en las exportaciones. Sin embargo, se pudo observar una disminución gradual de dicha condición, atribuido principalmente al incremento de las importaciones, lo que provoca una pérdida de competitividad (p. 1214).

Respecto al mercado de cebolla, del total de exportaciones enviadas por Honduras hacia el mundo, en promedio, el 90\% es importado por el MCCA, en especial, el principal destino de exportación es E1 Salvador. Con estos resultados se puede apreciar que existe poca cobertura de las exportaciones de cebolla hacia mercados distintos al de Centroamérica (Trade Map, 2020). En conexión con lo anterior, las exportaciones de cebolla de Honduras también representan un importante producto de exportación agrícola en la región, según la (SAG) (2014b) en su informe sobre Perfiles del Mercado de la Cebolla, Honduras es el tercer país que más produce dicha hortaliza en Centroamérica; en segundo lugar, Costa Rica que produce aproximadamente el doble que Honduras y; finalmente, Guatemala posicionado como el país que más produce y exporta cebolla de la región centroamericana (p.7). De hecho, cabe destacar que Honduras ha mostrado un incremento en las exportaciones de cebolla enviadas hacia Centroamérica, en especial en el año 2019, estos resultados son respaldados por el $\mathrm{BCH}$ (2019a) en su informe de comercio exterior, en el cual se contempla un incremento respecto al año 2018 de más de US\$ 11 millones en las exportaciones de legumbres y hortalizas enviadas hacia el resto del mundo (p.3). 


\section{AnTECEDENTES}

Es importante abordar un estudio sobre la competitividad de las exportaciones hondureñas para impulsar el desarrollo en los distintos sectores productivos ya que, a través de los resultados que se obtendrán, se puede fomentar la especialización y promover la innovación en los procesos productivos para cada uno de los productos analizados. Con los hallazgos, se podrá tomar mejores decisiones para diversificar no solamente la canasta exportadora de productos agrícolas como el cacao, miel natural y cebolla, sino para ser referentes en la venta de distintos bienes y servicios.

Actualmente Honduras carece de estudios oficialmente publicados sobre competitividad en el comercio internacional. Esta condición tiene repercusiones sobre la toma de decisiones de política comercial y limita las capacidades de negociación internacional ante la falta de información actualizada y confiable. En ese sentido surge la necesidad de realizar un estudio sobre las ventajas o desventajas comparativas de las exportaciones en esta área tan esencial para el desarrollo económico del país, ya que las consecuencias de no invertir en investigación sobre la competitividad de productos de exportación generan vacíos de información para una adecuada política exterior y, es notable que el mayor impacto que las decisiones de política comercial lo sufre el consumidor final y los productores nacionales.

Los resultados de la presente investigación pueden mostrar evidencia sobre cómo potenciar aquellos productos de exportación en los que el país posea ventajas comparativas y explotar el gran potencial de exportación al resto del mundo. En conclusión, los resultados derivados de la presente investigación servirán como aporte para las futuras decisiones de política comercial en Honduras.

En otros países, se han realizado estudios sobre la VCR, por ejemplo, Olvera (2018) en su estudio sobre el sector apícola mexicano, comparó los resultados del índice de VCR de Balassa y otro índice propuesto por Vollrath; en este caso en particular, los resultados son los mismos, situando a México en la posición número 12 de los valores promedio (3.7) de VCR analizado para 32 países de referencia durante el período 2000-2016. Dicho estudio fue realizado para los países exportadores de miel a nivel mundial (p.133).

Del mismo modo, Málaga y Williams, (2010) en su trabajo sobre La competitividad de México en la exportación de productos agrícolas, aplicó el índice de VCR propuesto por Balassa en el cual analizan las exportaciones del sector agropecuario entre los años 1991-2002. Los principales productos con una fuerte ventaja comparativa revelada para México son los vegetales, con valor mayor a cuatro. En términos generales, el país muestra clara ventaja comparativa en las exportaciones de vegetales y una débil ventaja comparativa en otros productos agropecuarios (p. 299).

En vista de lo anterior, se puede observar que existe evidencia de la competitividad mexicana en las exportaciones, por lo tanto, se puede aplicar el índice para el mercado de Centroamérica, especialmente para el mercado de Honduras y así poder realizar un análisis más profundo de las exportaciones agrícolas, ya que usualmente se analiza la competitividad en base al volumen exportado, no así con bases sólidas sustentadas con metodologías estandarizadas.

Por otro lado, en un estudio realizado por Oliveros y Pérez (2013), se implementó la metodología de las cinco fuerzas competitivas de Porter, dicha metodología busca determinar cuáles son las fuerzas competitivas de la industria del cacao en Colombia, según Oliveros y Pérez, este modelo puede explicarse con los siguientes factores: "la rivalidad entre competidores, el ingreso potencial de nuevos competidores, el poder de negociación 
de los proveedores, el poder de negociación de los compradores y la amenaza de productos sustitutos" (p.256). Según Akhtar et al. (2013) en su investigación sobre la competitividad sobre las exportaciones de productos de horticultura, se aplicó el índice de Balassa y los resultados mostraron que Pakistán posee ventaja comparativa en las exportaciones de mandarinas, de hecho, es un gran exportador ya que muestra una clara consistencia en su competitividad (p.92).

Por otro lado, en el año 2017, Sandoval y Zetina realizaron un estudio sobre la competitividad de las exportaciones de cebolla hacia los EE. UU. y el mundo, en dicha investigación, se concluyó que México presenta buenos resultados en el índice de ventaja comparativa revelada, por lo que son más competitivos en la exportación de cebolla hacia el mercado estadounidense y el resto del mundo, también se concluyó que Perú posee ventajas comparativas respecto a los mismos socios comerciales con los que México realizó el análisis (p.147). Cabe destacar que los países antes mencionados realizaron el estudio para un mercado en específico, sin embargo, para la presente investigación, se aplicará un análisis para el mercado global, comparando a cada uno de los miembros del MCCA.

En seguimiento a lo anterior, en el año 2017, Gonzáles también estudió las ventajas comparativas de productos agrícolas, en este caso para el mercado de Paraguay comparado con los países de Mercosur (Mercado Común del Sur), en el cual se evidencia el uso del índice de Balassa. En dicho estudio se muestra que los productos más competitivos son: la soja en grano, grasas animales, semillas de nabo, maíz, entre otros (p.21).

En seguimiento a los estudios de países centroamericanos, en Ecuador y China se han hecho estudios sobre competitividad utilizando más de una metodología. Lun-giao (2009) estudió las exportaciones de la miel y sus ventajas comparativas entre China y EE. UU, los resultados muestran los mayores niveles de ventaja comparativa en los años 90, con un índice de 6.55, sin embargo, en el transcurrir de los años, China ha perdido competitividad, evidenciado en el último registro del índice con valor de 1.33 en el año 2006 (p.19). Este último análisis coincide con lo expuestos anteriormente, en el cual dan prioridad al mercado norteamericano como uno de los principales importadores de productos agrícolas.

Al igual que el Mercosur, en Centroamérica también existe evidencia de estudios aplicando la VCR, Vargas (2014) muestra los 25 productos agrícolas con menor desempeño en la competitividad de las exportaciones, en donde se ubican las exportaciones de cacao en polvo guatemalteco. En los mismos resultados, se observa otro grupo de productos alimenticios provenientes de animales vivos que también fueron objeto de análisis.

Por otro lado, Garzón (2013) en su estudio sobre el mercado de cacao en Ecuador plantea que: "de acuerdo a los resultados de los indicadores, la ventaja comparativa revelada indica el grado de competitividad del Ecuador con respecto al mercado cacaotero mundial", ya que se posiciona favorablemente con un valor del índice de 36.22 , además, se concluyó que el país posee competitividad en su mercado interno, ya que es capaz de satisfacer la demanda doméstica junto con la demanda internacional (p.88). Este análisis es interesante, ya que el autor demostró que su país posee competitividad de las exportaciones de cacao al mundo, destacando que tiene una estructura productiva capaz de generar un excedente para exportar, lo que se puede interpretar como costos relativamente más bajos que la competencia.

Continuando con la VCR, otro de los estudios se ha realizado en Indonesia, donde se utilizó la metodología de la Ventaja Comparativa Revelada (VCR) que consiste en analizar las exportaciones de un país sobre algún producto, compararlo con las exportaciones totales hacia el país socio y las exportaciones totales al resto del mundo (Rifin, 2013, p.1). El análisis de Rifín se basa en la ventaja comparativa de las exportaciones de cacao en 
grano, sin embargo, Indonesia resultó ser el país menos competitivo comparado con otros países, este resultado es debido a que dichos países registran la exportación de cacao en grano como uno de los principales productos enviados al exterior y, por otro lado, Indonesia no depende en gran medida de la venta de este producto.

A continuación, como parte de la formulación del problema, se plantea la siguiente pregunta de investigación: ¿Honduras posee ventaja comparativa en las exportaciones, medido a través del índice de VCR respecto a los países del MCCA, para el mercado de cacao, miel natural y cebolla durante el periodo 2006-2019?

\section{ObjeTIVO GENERAL}

Explicar los principales hallazgos en el comportamiento de los resultados del IB para Honduras sobre las exportaciones de cacao, miel natural y cebolla respecto a los principales socios comerciales de la región del MCCA durante el período 2006-2019.

\section{OBJETIVOS ESPECÍFICOS}

- Determinar si Honduras posee competitividad medida a través del indicador de VCR de las exportaciones hondureñas de cacao, miel natural y cebolla respecto a los principales socios comerciales de la región del MCCA durante el período 2006-2019.

- Identificar los principales factores que influyen en los resultados de competitividad de las exportaciones hondureñas de cacao, miel natural y cebolla para los distintos mercados en los que se realiza el estudio.

\section{HiPÓTESIS}

Ha1: Honduras sí posee ventaja comparativa en las exportaciones de cacao y sus preparaciones medido a través del índice de VCR respecto a los socios comerciales del MCCA.

Ha2: Honduras sí posee ventaja comparativa en las exportaciones de miel natural medido a través del índice de VCR respecto a los socios comerciales del MCCA.

Ha3: Honduras sí posee ventaja comparativa en las exportaciones de cebolla medido a través del índice de VCR respecto a los socios comerciales del MCCA. 


\section{Marco CONCEPTUAL}

\subsection{Perspectiva teórica}

\subsubsection{Teoría de la Ventaja Absoluta de Adam Smith}

El célebre economista Adam Smith, acuñó el término de ventaja absoluta en su libro "La Riqueza de las naciones" en el año 1776. En dicha obra, trató de explicar el origen de la riqueza de los países y su papel en el comercio internacional (Rodríguez, 1994, pp. 7-8). Según (Guerrero, 1995) el origen de la teoría de la ventaja absoluta de Smith se fundamenta en la capacidad que tienen las empresas y países de producir al menor coste de producción. Si un país tiene empresas con ventaja absoluta en distintos sectores productivos relevantes, dicho país tendrá ventaja absoluta en el comercio exterior y se convertirá en un país exportador, obteniendo beneficios en las exportaciones netas (p.13).

La ventaja absoluta es una teoría fundamentada en las horas de trabajo que se requieren para producir un bien o servicio, la característica principal de este enfoque, es que los requerimientos de trabajo por unidad producida no se aplican en términos relativos o en términos de otro bien. Únicamente se comparan las horas de trabajo de un bien en ambos países y se determina qué país es más eficiente en la producción. Por lo tanto, se dice que existe ventaja absoluta: "Cuando un pais puede producir una unidad de un bien con menos trabajo que otro pais" (Krugman et al., 2012, p.30). Sin embargo, no se puede utilizar la ventaja absoluta para determinar un patrón del comercio internacional, ya que los precios relativos de los bienes producidos son determinados por la interacción en el mercado internacional, no solamente por la estructura productiva doméstica de un país, por lo tanto, es necesario la interpretación de la productividad del trabajo en términos relativos.

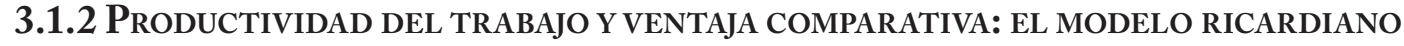

La ventaja comparativa es un término económico desarrollado por el economista David Ricardo en el siglo XIX, como una versión mejorada de la ventaja absoluta de Smith. La ventaja comparativa parece una definición fácil de entender, sin embargo, puede dar lugar a confusiones. El economista y ganador del Premio Nobel, Paul Samuelson, desarrolló importantes aportes para comprobar la veracidad de dicha terminología, considerándola como una teoría aceptada y aplicable a los principios económicos vigentes. (Krugman et al., 2012, p. 25).

Por otro lado, la ventaja comparativa propuesta por David Ricardo hace énfasis en las ganancias comerciales derivadas de la libre interacción comercial entre países compradores y vendedores, en ese sentido, Jaramillo plantea que el comercio siempre será beneficioso para aquellos países que asignen los recursos escasos con el menor costo relativo posible. Y plantea que, básicamente, la teoría ricardiana se fundamenta principalmente en los diferentes costos relativos de la fuerza de trabajo de los países (Jaramillo, 2017, p. 10).

E1 modelo ricardiano se enfoca en la ventaja comparativa derivada de las diferencias en la estructura productiva de los países; reflejado en la productividad del trabajo. Por lo tanto, la decisión de los países sobre qué exportar depende de aquellos productos en los que posee ventaja comparativa y así, obtener los beneficios del comercio cuando se intercambian mercancías con otros países.

En el comercio internacional se logran producir grandes cantidades de bienes y servicios debido a que el comercio entre países les permite especializarse en productos específicos en los que poseen ventaja comparativa. "Un país tiene ventaja comparativa en la producción de un bien si el coste de oportunidad en la producción 
de este bien, en términos de otros bienes, es inferior en este país de lo que es en otros países" (p.27). E1 coste de oportunidad es un término económico utilizado en el comercio internacional para representar los costos relativos que tiene un país para producir un bien o servicio, de este modo, se comparan los costos de un bien en términos de otro bien para reflejar qué producto posee los costos relativamente más bajos y, por ende, posee ventaja comparativa en su producción respecto a otros países (Krugman et al., 2012, p.27).

Para finalizar con el concepto de Productividad del Trabajo, el autor plantea que la ventaja comparativa en la producción de bienes y servicios, medida a través de la productividad relativa del trabajo, se expresa en los requerimientos de trabajo por unidad producida, que básicamente son las horas de trabajo necesarias para producir una unidad de un bien en términos de otro bien dados los factores de producción.

\subsubsection{EL MODELO DE LOS FACTORES ESPECÍFICOS}

El modelo de factores específicos fue acuñado por Paul Samuelson y Ronald Jones, este modelo tiene ciertas similitudes con el modelo de ventaja comparativa de David Ricardo, la diferencia consiste en que el modelo de factores específicos permite la incursión de factores específicos adicionales al factor trabajo; y el único factor que es móvil entre sectores productivos, es el factor trabajo. Para los factores productivos, en el modelo de factores específicos, se definen capital y tierra, a los que se le asignan los sectores de manufactura y alimentos, respectivamente.

Krugman et al., (2012) plantea que cuando los economistas hablan sobre la aplicación del modelo de factores específicos no se refieren a una condición permanente, sino a la utilización del factor en un período de tiempo limitado, por lo tanto, la diferencia entre factores específicos y factores móviles en la producción no es tan fácil de definir, depende mucho del tiempo necesario que requiera trasladar un factor de una industria a otra (p. 53).

\subsubsection{El MOdElo Heckscher-OHLiN}

Krugman et al. (2012) plantea que la principal diferencia de este modelo respecto al modelo ricardiano es que refleja las diferencias en los recursos de los países, el modelo ricardiano solamente hace énfasis en las ventajas comparativas derivadas de la productividad relativa de bienes y servicios. Sin embargo, en la práctica, las diferencias de recursos para la producción son los detonantes de las ganancias del comercio. Y explica que:

Este modelo muestra que la ventaja comparativa se ve afectada por la interacción entre los recursos de las naciones (la relativa abundancia de factores de producción) y la tecnología de producción (que influye en la intensidad relativa con la que los diferentes factores de producción son utilizados en la producción de diferentes bienes). (Krugman et al., p.81).

E1 teorema Heckscher-Ohlin plantea que, los paises exportarán aquel bien que utilice intensivamente el factor relativamente más abundante en su producción. Se puede apreciar que la definición es distinta a la ventaja comparativa de David Ricardo, en la que se hace énfasis en las exportaciones de aquel bien cuyo coste de oportunidad sea menor en un país comparado con otro país.

Por otro lado, Villarreal et al. (2020) define el efecto de la apertura comercial para el modelo de HeckscherOhlin: 
Expone el movimiento en precios causado por dicha apertura, situando primero los países en el escenario de autarquía y posteriormente, en un escenario con comercio internacional. En un estado de autosuficiencia, dependiendo de la abundancia de los factores, los países se especializan parcialmente en los bienes que son intensivos en el factor abundante, siendo menor el precio relativo de estos bienes, estableciéndose así un precio autárquico.

Según (Pimentel, 2014), el modelo de Heckscher-Ohlin es la base fundamental de otros teoremas importantes para analizar el comercio internacional, especialmente "el teorema de Stolper-Samuelson, el teorema de Rybczynski y el teorema de igualación de los precios de los factores”.

El teorema de Heckscher-Ohlin se basa en algunos supuestos, principalmente los siguientes: solo existen dos países para comerciar, dos bienes y dos factores productivos; el factor tecnológico es igual en ambos países (no existen diferencias); existen rendimientos constantes a escala y los dos bienes utilizan intensivamente los factores de producción de manera diferente, lo que significa que, para cada bien, la intensidad con la que se utiliza el factor productivo es diferente (pp. 43-44).

Otros autores, como Krugman et al. (2012), explican que la teoría de Heckscher y Ohlin resalta cómo interactúan las proporciones de los diferentes factores productivos con los que cuentan los países y en qué medida son utilizados dichos factores, por esa razón, también se le conoce como la teoría de las proporciones factoriales.

\subsection{5 Índice de Balassa: La Ventaja Comparativa Revelada (VCR)}

Para este estudio, se aplicará el índice de ventaja comparativa revelada, también conocido como "índice de Balassa" (IB), "compara la participación de un producto exportado por un país hacia un mercado, tomando como referencia las exportaciones del mismo sector realizado por un grupo de países competidores”. El índice de VCR se aplica para estudiar las ventajas comparativas de las exportaciones de un producto o una industria que son enviadas a los socios comerciales. La metodología compara el valor monetario de las exportaciones de un país con las importaciones del mismo producto que provienen desde los socios comerciales, la comparación se puede realizar con un solo país o bien, con un bloque económico o región (González, 2017, pp. 14-15).

Vargas (2014) interpreta la aplicación de la ventaja comparativa revelada de la siguiente manera:

La comparación del valor del índice correspondiente a varios productos de un mismo país, permite identificar aquellos productos en los que dicho país tiene mayores ventajas comparativas; mientras que la comparación del valor del índice entre varios países para un mismo producto, permite identificar aquellos países con mayores ventajas comparativas para dicho producto.

Existen distintas metodologías para los índices de ventaja comparativa revelada, sin embargo, quien acuñó el término fue el economista húngaro Bela Balassa en el año 1965. Balassa trató de dar respuesta a ciertas limitaciones que, según él, existen en la metodología de la ventaja comparativa, dicho autor consideraba que la principal limitación de este concepto era su aplicación práctica en el mundo real, aduciendo que "las ventajas comparativas son resultado de muchos factores, unos que no se pueden medir y otros que son muy difíciles de determinar" (Arias \& Segura, 2004).

En seguimiento a lo anterior, Olvera, (2018) plantea la ventaja comparativa relevada como una alternativa 
ante las dificultades existentes para medir las ventajas comparativas de los países en el comercio internacional, de hecho, el economista húngaro no descarta la importancia de la teoría de Heckscher-Ohlin y el modelo de David Ricardo. Sin embargo, el análisis para el modelo de Heckscher-Ohlin se vuelve muy difícil de interpretar incluyendo tres factores de producción y más aún, incluyendo más de dos países a la aplicación de la metodología (p. 103).

Olvera, en su tesis sobre Ventaja comparativa del sector apicola de México en el comercio internacional de miel, periodo 2000-2016 plantea que:

La ventaja comparativa "relevada" puede ser indicada por el desempeño comercial de los países individuales, con respecto a los productos manufacturados, en el sentido de que el patrón de comercio de mercancía refleja costos relativos, así como diferencias en factores no relacionados con precios.

En conexión a lo anterior, con el índice de Balassa se espera que las ventajas comparativas muestren el potencial de la canasta exportadora de cada país, bajo el supuesto que en todos los países analizados existen homogeneidad en sus gustos y preferencias y, además, asumiendo una aplicación uniforme de aranceles para cada país en las respectivas industrias analizadas. En ese sentido, para reflejar ventaja comparativa en las exportaciones de un país, se debe contar con una proporción de las exportaciones superior a las importaciones, de este modo, en la medida que las exportaciones sean mayores, el valor del índice será más alto, lo que significa que posee ventaja comparativa relevada o, dicho de otro modo, el desempeño de las exportaciones del país en cuestión es mejor que el resto de los países de la región estudiada.

Olvera (2018) explica que parte fundamental del índice de Balassa es la participación relativa de las exportaciones, que se obtiene con el primer cociente de la formula del índice de Balassa, planteado como el valor de las exportaciones realizadas de un país para un producto determinado dividido entre el valor de las exportaciones de distintos productos enviados al grupo de países socios, la participación es relativa ya que se está comparando la exportación de un producto con el resto de mercancías.

Según (Arias \& Segura, 2004), la aplicación práctica de la VCR entre socios comerciales para analizar las ventajas en las exportaciones de un mismo producto o industria "son consistentes con la teoría económica". Los resultados permiten medir las ventajas comparativas de las exportaciones sin la necesidad de recurrir al estudio de los precios relativos ajustados por las fuerzas del mercado. El índice de VCR de Balassa, básicamente compara las exportaciones que un país realiza hacia un grupo de países competidores, con las importaciones que este país realiza desde dichos países competidores. La comparación es sobre el mismo producto y el resultado se considera como una fuerte ventaja comparativa en las exportaciones del producto analizado si el valor de VCR es mayor que cuatro (González, 2017). 


\section{Metodología}

En la presente investigación, se utiliza un enfoque de investigación cuantitativo, con un diseño de investigación no experimental; ya que no se realiza manipulación o alteración de las variables. Además, el alcance de investigación es de tipo descriptivo ya que se busca analizar el comportamiento de la competitividad y dar seguimiento a la evolución mostrada durante la serie de tiempo objeto de análisis. Las variables para utilizar son las exportaciones de cacao y sus preparaciones, miel natural y cebolla, asimismo se incorporan las exportaciones totales de bienes enviadas al resto del mundo, utilizando como unidades de análisis a los países de Centroamérica (Honduras, Costa Rica, Guatemala, El Salvador, Nicaragua).

La información para el cacao se recolectó mediante una búsqueda por jerarquía o capítulo 18; acerca de cacao y sus preparaciones, en el cual se incluyen todas sus presentaciones: cacao en grano, pasta de cacao, manteca de cacao, cacao en polvo, chocolate, entre otros. Por otro lado, la consulta para la miel natural se realizó en la jerarquía o capítulo 04; en el cual se incluyen Productos lácteos, huevos de ave y miel natural, productos comestibles de origen animal, finalmente se seleccionó la jerarquía 0409 correspondiente a la miel natural.

Para la cebolla, se consultó el capítulo 07; hortalizas comestibles y determinadas raíces y tubérculos, para finalizar la consulta se seleccionó la numeración 070310 que corresponde a cebollas y chalotes (chalotes es una variedad de las cebollas).

Los datos estadísticos de las exportaciones requeridas se obtuvieron de fuentes secundarias, especialmente de Trade Map mediante la consulta y descarga de bases de datos. Del mismo modo, se obtuvo información de $\mathrm{BCH}$, la SAG y de distintos estudios internacionales en los cuales se utilizan índices de VCR para la competitividad de productos de exportación.

La literatura reporta tres métodos de cálculo del índice de VCR expuestos por Gonzales (2017). El primer método llamado VCR restringida, un índice de Balassa (IB) con algunas variantes que "mide el grado de importancia de un producto dentro de las exportaciones de un mercado a otro mercado, versus la importancia de las exportaciones del producto local de interés sobre las exportaciones totales del país local al resto del mundo" (p.24). El segundo método llamado indice de Priorización de Mercados, se concibe como un indicador mejorado respecto al primero en el sentido que registra aquellas exportaciones con relativa ventaja hacia un país socio, no obstante, Gonzáles (2017) destaca que el cálculo de este índice genera una pérdida de información de aquellos productos que fueron exportados únicamente al mercado específico de análisis, pero que no fueron exportados a ningún otro mercado" (p.14). El tercer método llamado VCR de Bela Balassa (IB), el cual compara la participación de un producto exportado por un país hacia un mercado, tomando como referencia las exportaciones del mismo sector realizado por un grupo de países competidores" (p.16).

A continuación, se presenta la fórmula propuesta para el índice de VCR:

Figura 1 Fórmula del indice de VCR.

$$
V C R_{A}^{k}=\frac{X_{A}^{k} / X_{A}}{X_{r e f}^{k} / X_{\text {ref }}}
$$

Fuente: Gonzáles (2017) 
$\mathrm{X}_{\mathrm{A}}^{\mathrm{k}}$ : exportaciones del producto $\mathrm{K}$ del país $\mathrm{A}$ hacia el resto de países del mundo.

$\mathrm{X}_{\mathrm{A}}$ : exporta ciones totales del país A hacia el resto de países del mundo.

$\mathrm{X}^{\mathrm{k}}$ ref : exportaciones del producto $\mathrm{K}$ de países competidores de referencia hacia mundo.

$\mathrm{X}_{\mathrm{ref}}$ : exportaciones totales de países competidores de referencia hacia el mundo.

(Para más detalles sobre el índice, vea la formula (4) de Gonzáles, 2017, p.15).

Es importante mencionar que, por ejemplo, si se está analizando la VCR de cacao para Honduras, entonces los competidores de referencia corresponden al resto de países de la región (Costa Rica, Guatemala, E1 Salvador y Guatemala) y, por lo tanto, el valor de las exportaciones de cacao de dichos competidores es la suma de los cuatro.

En vista de lo anterior, esta versión de VCR es la mejor para medir la competitividad, la diferencia fundamental entre los dos enfoques anteriores para calcular el índice de Balassa es el marco de referencia. En la interpretación de Durán y Alvarez (2008) se compara, como ya se ha dicho antes, si las exportaciones de un commodity, sector o industria de un determinado país son más importantes hacia un mercado específico que hacia el resto del mundo. En este caso, el marco de referencia consiste en la distribución de las exportaciones enviadas al mundo (p.16). Es importante mencionar que uno de los principales problemas para la interpretación del tercer índice, es que no presenta un rango claro para los resultados, ya que puede mostrar valores desde cero hasta infinito, por lo cual, si VCR es igual a 1, o bien, los valores de VCR $<1$, significa que no existe ventaja comparativa. Solamente los valores de VCR > 1 muestran ventajas comparativas en la industria analizada.

Para la interpretación de los resultados obtenidos por medio del índice, Gonzáles plantea la siguiente tabla de interpretación de los valores posibles para el IB:

Tabla 1 Valores posibles para el indice de Balassa de VCR.

\begin{tabular}{r|l}
\hline Valor del Índice & Interpretación \\
\hline $0<V C R \leq 1$ & No existen ventajas comparativas. \\
$1<V C R \leq 2$ & Existe una débil ventaja comparativa. \\
$2<V C R \leq 4$ & Existe una moderada ventaja comparativa. \\
$4<V C R$ & Existe una fuerte ventaja comparativa. \\
\hline
\end{tabular}

Fuente: Gonzáles (2017): “Competitividad de las Exportaciones: Un análisis teórico de indicadores de Ventajas Comparativas Reveladas y su aplicación a los datos de comercio de Paraguay". 


\section{FuenTES DE DATOS}

Los datos utilizados para esta investigación provienen de Trade Map y del $\mathrm{BCH}$ para realizar un análisis entre países.

\section{DisCuSIÓN Y ANÁLISIS DE RESULTADOS}

\subsection{Panorama de la Actividad Económica en Honduras}

La economía hondureña tiene un grado de dependencia de la producción y exportaciones de productos agrícolas. Según datos publicados por el Banco Central de Honduras (BCH) (2019a), se observa que la actividad agrícola refleja un crecimiento promedio anual de $0.3 \%$ y la actividad agroindustrial ha crecido en un $22 \%$, notables diferencias entre los productos básicos agrícolas contra otros que requieren de un proceso industrial para ser exportados. Por otro lado, el PIB real por el enfoque de la producción muestra que el sector agrícola refleja un bajo crecimiento en su producción, con un promedio anual en los últimos años de 4\%, esto comparado con el sector de Intermediación financiera, Comunicaciones y el sector manufacturero, con un promedio anual de 12\%, 9\% y 4\%, respectivamente (BCH (2019b).

En la figura 2 se observa el valor de las exportaciones hacia el resto del mundo de la actividad agrícola y agroindustrial. Las exportaciones totales están representadas por el gráfico de línea.

Figura 2 Exportaciones por actividad económica (2006-2019).

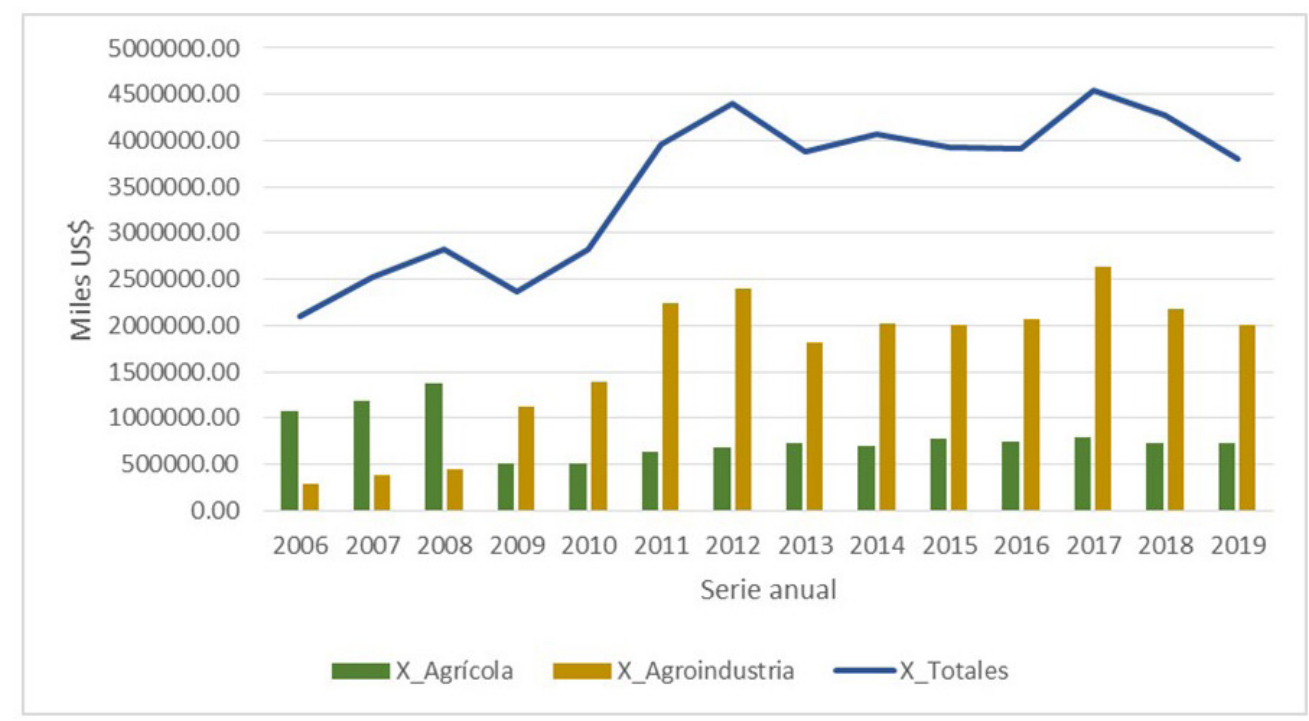

Fuente: Elaboración propia con datos del Banco Central de Honduras (BCH): Informe de Comercio Exterior de Mercancías Generales. 
Según el BCH (2019a), una de las razones por las cuales el sector agroindustrial y agrícola incrementó el volumen de exportaciones es debido a que se abrieron nuevos mercados para exportar. Se observa que ambos sectores han aumentado el monto de las exportaciones a partir del año 2008 y 2009, siendo el sector agroindustrial el que tuvo un gran impulso, no así con el sector agrícola que refleja un incremento, pero menos significativo. En relación a lo anterior, se realizó una comparación de los datos del BCH (2019c) en el Sistema Integrado del Comercio Exterior, para analizar la participación de las exportaciones de cebolla entre los períodos 2006-2019, los resultados representan menos del 1\% del total de exportaciones del sector agrícola. Esto demuestra que la cebolla no representa uno de los principales productos de exportación. Por otro lado, los productos que más participación tienen sobre el total de exportaciones agrícolas y agroindustriales son: café, banano, melones, sandías, aceite de palma y camarones (BCH, 2019a, p.2). Cabe destacar que, pese a mostrar un incremento en el volumen de las exportaciones de productos agrícolas, ese aumento no se ve reflejado significativamente en la estructura porcentual de las exportaciones de cacao, miel natural y cebolla.

Tomando en cuenta que, según el documento sobre el perfil del mercado de cebolla publicado por la SAG (2014), el principal exportador centroamericano de cebolla hacia el resto del mundo es Guatemala y en segundo lugar Costa Rica, se puede deducir que los bajos niveles de exportación de cebolla de Honduras a lo largo del tiempo se deben a una falta de competitividad y que el sector no ha recibido suficiente apoyo (p.9).

En la Tabla 2, se ilustran las exportaciones realizadas por cada país de la región centroamericana, de este modo, se plantea una introducción, con lo que se desarrollará el análisis de los resultados obtenidos.

Tabla 2 Exportaciones centroamericanas enviadas al mundo (miles de dólares US\$) (2006-2019).

\begin{tabular}{llllll}
\hline Producto & Honduras & Guatemala & Costa Rica & El Salvador & Nicaragua \\
\hline Cacao & 23810 & 133051 & 128644 & 72686 & 67899 \\
Miel & 40 & 72866 & 29 & 61121 & 23893 \\
Cebolla & 4041 & 68018 & 2117 & 23 & 6766 \\
\hline
\end{tabular}

Fuente: Elaboración propia con datos de Trade Map.

Como introducción a los valores de VCR, en la Tabla 2 se muestran las exportaciones de cada uno de los países centroamericanos, acumulado durante el período 2006-2019. Se puede apreciar que el principal exportador de cacao es Guatemala, y como se podrá observar en el análisis de resultados, este país muestra los registros más altos de VCR, aunque no suficiente para ser competitivo. Para el caso de Honduras, los tres productos objeto de análisis; cacao, miel natural y cebolla, muestran notables diferencias en los flujos de divisas por exportaciones.

El producto que más destaca y el más fuerte es el cacao y sus preparaciones, de hecho, según la (SAG, 2014a) en su informe sobre el mercado de cacao, en la región centroamericana existen tres principales productores de cacao, destacan Guatemala en primer lugar, seguido de El Salvador y Honduras. 
Durante el período entre los años 2006-2019, el volumen de exportaciones de cacao hondureño al mundo representa en promedio 799,319 kg (BCH, 2019c). A continuación, se ilustra en la Figura 3 las exportaciones hondureñas de cada uno de los productos analizados.

Figura 3 Exportaciones hondureñas de cacao, cebolla y miel natural enviadas al mundo (2006-2019) (en miles de dólar y porcentajes).

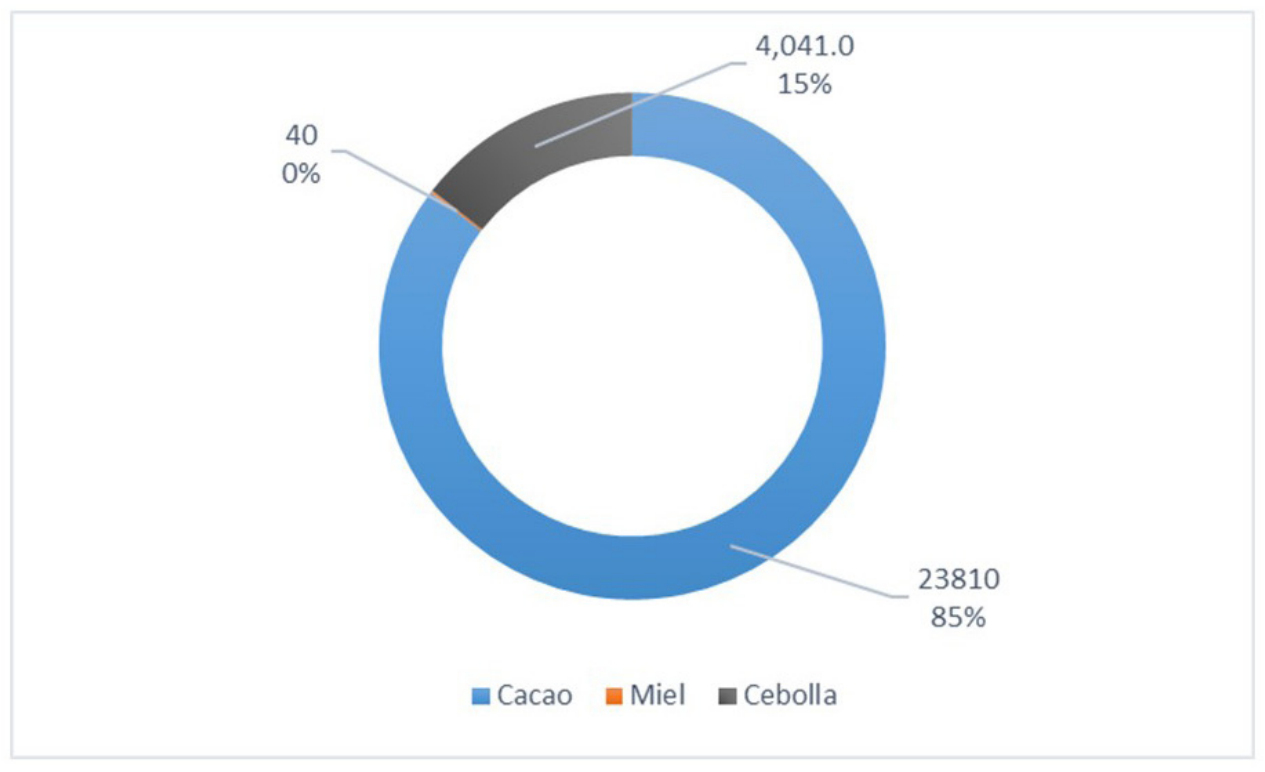

Fuente: Elaboración propia con datos de Trade Map

Según el documento sobre el perfil del mercado de cebolla publicado por la SAG (2014), el principal exportador centroamericano de cebolla hacia el resto del mundo es Guatemala, además, explica que entre los años 20052013 "el bajo volumen de exportaciones hacia Honduras es por la producción nacional de Honduras durante ese periodo del año; y entre septiembre a diciembre lo bajos niveles de exportaciones es por los bajos niveles de producción de Guatemala” (p.10). En ese sentido, se puede afirmar que Honduras no es un gran exportador de cebolla, siendo el tercer mayor importador de este producto proveniente de Guatemala.

Las exportaciones de miel natural representan una pequeña cantidad, de hecho, mucho menor que el cacao y la cebolla. Según la (SAG, 2016) en su documento Análisis de Coyuntura del Cultivo de Miel de Abeja en Honduras, el comportamiento de la producción nacional se ha mostrado muy volátil y se prevé que la cantidad de miel en el mercado nacional depende al menos en un 50\% de las importaciones (p.7). Considerando que el volumen de las exportaciones de miel natural ha disminuido, cabe destacar que representa una participación muy pequeña, menos del $0.01 \%$ de las exportaciones totales de bienes agrícolas del país en todos los años objeto de estudio, con esta información se puede comprobar que la producción y exportación de miel natural es una absoluta minoría comparado con los principales productos agrícolas. Se han exportado, en promedio 1,693 Kg de miel al resto del mundo $(\mathrm{BCH}, 2019 \mathrm{c})$. 


\subsection{ANÁlisis de RESULTAdos DEL ÍNDICE DE VCR}

El índice de Balassa de VCR del cacao muestra los peores registros para Honduras, en la Figura 4 se puede observar que en todos los años estudiados se muestra la VCR entre cero y uno, esto significa que Honduras no posee ventaja comparativa en las exportaciones de cacao enviadas al mundo respecto a los socios comerciales del MCCA. En ese sentido, la industria del cacao es más competitiva para las exportaciones del resto de países del MCCA en su conjunto que para Honduras, cabe destacar que estos resultados sólo comparan la competitividad en el mercado centroamericano, por lo tanto, no necesariamente Honduras es menos competitivo respecto a otros mercados en América Latina y El Caribe o Norteamérica.

Figura 4 Comportamiento de VCR en las exportaciones centroamericanas de cacao hacia el mundo.

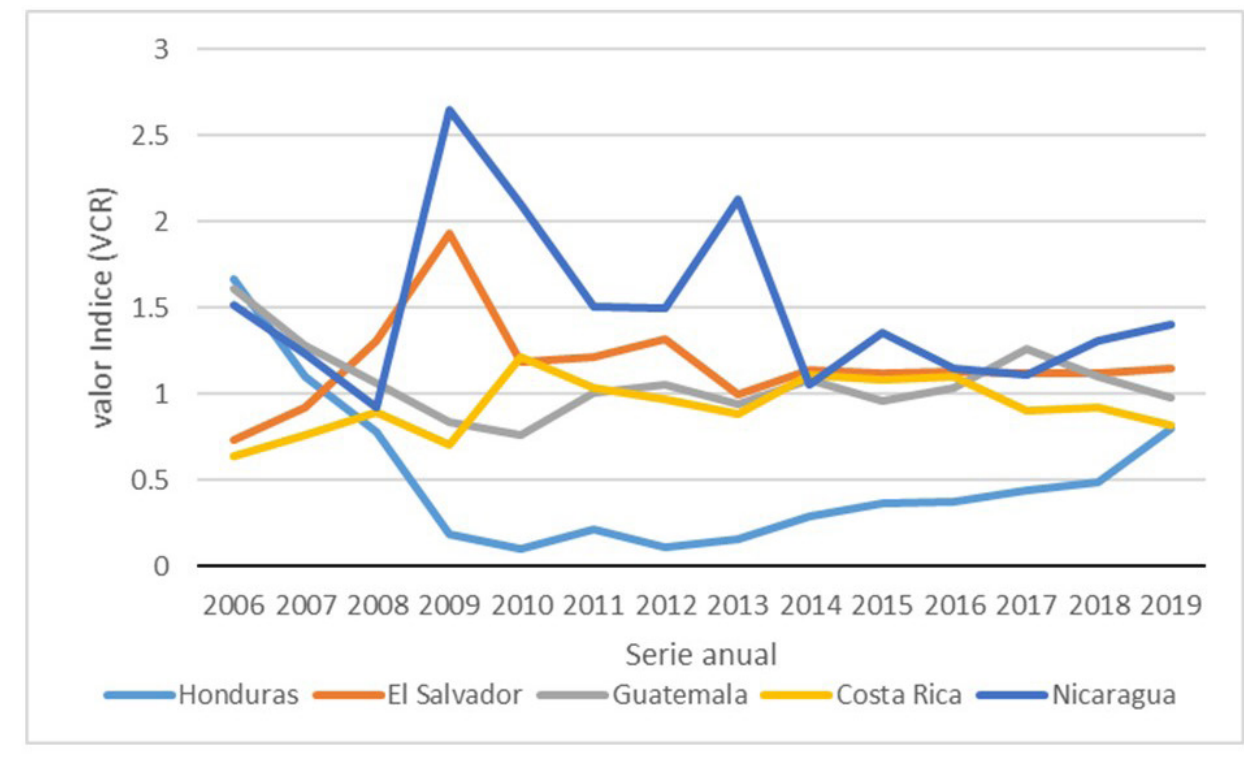

Fuente: Elaboración propia con datos de Trade Map

En la figura 4, se puede observar que los mejores registros los tiene Nicaragua, con un índice de VCR mayor que uno a partir del año 2008; además, en promedio, posee la mayor ventaja comparativa con $\mathrm{VCR}=1.4959$. En segunda posición se encuentra E1 Salvador, con valor promedio de VCR $=1.1705$. El resto de países muestra valores entre 0.5 y 2 , eso es porque, por ejemplo; las exportaciones individuales de cacao que realiza Guatemala enviadas hacia el resto del mundo, son menos competitivas que Nicaragua y El Salvador. Es interesante el ejemplo mostrado anteriormente ya que, según la (SAG, 2014a), Guatemala es el mayor exportador de cacao en grano en Centroamérica, sin embargo, los resultados sugieren que, las exportaciones de cacao no son más competitivas que otros países de la región. Por otro lado, se demuestra que no basta con registrar un alto volumen de exportaciones en valores absolutos, ya que no necesariamente equivale a mayor competitividad, y viceversa, ya que Nicaragua es uno de los países con el menor monto de exportaciones de cacao en la región, sin embargo, resultó ser el más competitivo pese a una disminución de exportación a partir del año 2014, comportamiento atribuido a un bajo crecimiento de las exportaciones de cacao, comparado con las exportaciones totales de bienes que mostraron un mejor desempeño. 
Tabla 3 Resultados obtenidos de VCR en las exportaciones de cacao (2006-2019).

\begin{tabular}{rrrrrr}
\hline \multicolumn{1}{l}{ Año } & \multicolumn{1}{c}{ Honduras } & El Salvador & \multicolumn{1}{l}{ Guatemala } & Costa Rica & \multicolumn{1}{c}{ Nicaragua } \\
\hline 2006 & 1.670317693 & 0.736101163 & 1.615185959 & 0.637223641 & 1.512558345 \\
2007 & 1.099237187 & 0.919649105 & 1.277930102 & 0.763718794 & 1.23219695 \\
2008 & 0.784239605 & 1.307785639 & 1.059752826 & 0.895582343 & 0.91999874 \\
2009 & 0.186977277 & 1.929855844 & 0.838430002 & 0.703698894 & 2.649664078 \\
2010 & 0.105394532 & 1.189924172 & 0.760588662 & 1.212357739 & 2.096957964 \\
2011 & 0.216248843 & 1.210621426 & 1.01041619 & 1.037576183 & 1.50921935 \\
2012 & 0.115823782 & 1.317450886 & 1.052880046 & 0.967904029 & 1.501703292 \\
2013 & 0.155071589 & 0.997028656 & 0.940007823 & 0.888459356 & 2.130280343 \\
2014 & 0.289702049 & 1.140919526 & 1.082276779 & 1.115497462 & 1.055760522 \\
2015 & 0.367596308 & 1.117534707 & 0.96005068 & 1.084388897 & 1.356802124 \\
2016 & 0.37484069 & 1.133589864 & 1.031469577 & 1.097735745 & 1.151752585 \\
2017 & 0.444493942 & 1.12367766 & 1.262122274 & 0.902340137 & 1.106583907 \\
2018 & 0.486470839 & 1.1163296 & 1.099928469 & 0.920656338 & 1.313415793 \\
2019 & 0.80174676 & 1.146900738 & 0.983487848 & 0.821264892 & 1.40638279 \\
\hline
\end{tabular}

Fuente: Elaboración propia con datos de Trade Map

En la tabla 3 se observan los resultados obtenidos de calcular el índice de VCR de cacao exportado al mundo, el índice se desarrolló para cada uno de los países de la región, de este modo, para cada país se analizaron las exportaciones enviadas hacia el resto de los socios centroamericanos. Se puede observar que en el sector apícola (miel natural) en Honduras, no posee ventaja comparativa, de hecho, junto con Costa Rica registran los resultados más bajos de la VCR con valor promedio de cero, respectivamente. Para el caso de Honduras, este comportamiento está directamente relacionado con el bajo nivel de exportaciones hacia el mundo, de hecho, el país registró un bajo nivel de divisas por exportaciones a partir del año 2014, como consecuencia, las importaciones provenientes del resto de países de la región se incrementaron y esto generó un índice menos favorable.

En el caso de Costa Rica, no presenta exportaciones de miel natural en la mayoría de los años objeto de análisis, ya que al igual que Honduras se dedica a abastecer el mercado local, lo que refleja la baja competitividad. 
Figura 5 Comportamiento de VCR en las exportaciones centroamericanas de miel hacia el mundo.

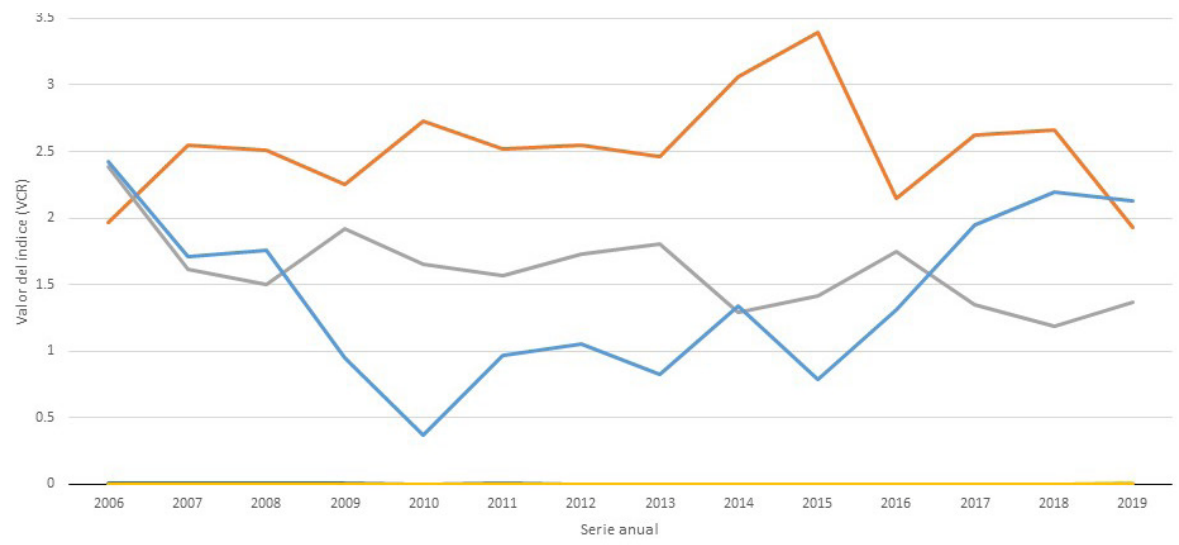

En la figura 5 se puede observar el comportamiento de la ventaja comparativa de la miel en los países centroamericanos, evidenciando que El Salvador es el país más competitivo. Cabe destacar que el mayor exportador de miel natural en la región, es Guatemala, sin embargo, se observa una pérdida de competitividad a partir del año 2010, asociado a un incremento sustancial de las exportaciones de los competidores de referencia de Centroamérica y, por el contrario, una disminución en el monto de exportaciones guatemaltecas, lo que provocó un índice desfavorable; en ese sentido, los resultados de El Salvador también logran demostrar que pese a no ser el país más exportador de miel natural, sí registro el mayor índice de competitividad. Como se puede observar en la Tabla 4, El Salvador refleja un valor promedio de VCR igual a 2.52, dicho resultado refleja la posición más competitiva de la región, con una moderada ventaja comparativa, lo que significa que el desempeño de las exportaciones salvadoreñas es mucho mejor que el resto de los países centroamericanos.

Tabla 4 Resultados obtenidos de VCR en las exportaciones de miel natural (2006-2019).

\begin{tabular}{rrrrrr}
\hline Año & \multicolumn{1}{l}{ Honduras } & El Salvador & \multicolumn{1}{l}{ Guatemala } & Costa Rica & \multicolumn{1}{l}{ Nicaragua } \\
\hline 2006 & 0.010123399 & 1.964077452 & 2.387928191 & 0 & 2.424631582 \\
2007 & 0.00844852 & 2.549081515 & 1.61154642 & 0.001131551 & 1.712513196 \\
2008 & 0.00509752 & 2.508584494 & 1.505354925 & 0 & 1.758136451 \\
2009 & 0.011116653 & 2.254408483 & 1.918583886 & 0 & 0.95081611 \\
2010 & 0 & 2.73068176 & 1.652774491 & 0 & 0.371732172 \\
2011 & 0.00318208 & 2.519134044 & 1.565820277 & 0 & 0.969923549 \\
2012 & 0.000611477 & 2.551538868 & 1.733277636 & 0 & 1.05193048 \\
2013 & 0.001142972 & 2.460296515 & 1.80624675 & 0 & 0.823651804 \\
2014 & 0 & 3.063590923 & 1.288617949 & 0 & 1.342159356 \\
2015 & 0 & 3.397490699 & 1.411807096 & 0 & 0.789621425 \\
2016 & 0.000817984 & 2.143614135 & 1.744764217 & 0 & 1.309703345 \\
2017 & 0.001856277 & 2.625387988 & 1.346827057 & 0 & 1.947683329 \\
2018 & 0.001853609 & 2.660082939 & 1.187100185 & 0 & 2.195536602 \\
2019 & 0.001397156 & 1.924557855 & 1.363649342 & 0.01018165 & 2.126426942 \\
\hline
\end{tabular}


Considerando los resultados de la Tabla 4, se puede analizar que Honduras tiene poca participación en el mercado mundial de miel natural, aunado a lo anterior, la SAG (2016) explica que los dos principales destinos de exportación son Australia y EE. UU, el segundo con una participación un poco mayor al 50\% del total de exportaciones de este producto (p.10). Además, según datos del BCH (2019c), el volumen promedio de miel natural exportado al mundo durante los años 2006-2019 fue de 1,693 Kg, mucho menor a los 799,319 kg registrados de exportaciones de cacao. Para el índice de VCR; E1 Salvador, Guatemala y Nicaragua presentan los mejores resultados de la VCR, cabe señalar que entre los años 2006-2019, dichos países centroamericanos registraron una disminución en las exportaciones de miel, sin embargo, el resto de los países también tuvieron un comportamiento similar, por lo tanto, el valor de VCR no fue afectado a tal grado de disminuir el nivel de competitividad promedio. Se puede concluir que los tres países poseen los mejores resultados en el MCCA, donde Guatemala y Nicaragua con una VCR promedio de 1.61 y 1.41, respectivamente y El Salvador que registró un promedio alrededor de 2.53 .

En el mercado de la cebolla (incluso chalotes), para el caso de Honduras, se observa un índice de VCR menor que 1 durante el período 2006-2019, mostrando que no cuenta con ventaja comparativa en el mercado de la cebolla. De hecho, a partir del año 2018 el índice muestra VCR más cercano a cero, lo que significa que el país no es competitivo en este mercado. Este comportamiento está asociado a una disminución de las exportaciones enviadas hacia el mundo y, además, explicado por un incremento de estas por parte del resto de países de la región, principalmente impulsado por Guatemala.

En la Tabla 5 se puede observar que el único dato en el que Honduras alcanzó una débil ventaja comparativa fue en el año 2013, este resultado está asociado a un importante incremento de las exportaciones respecto al año 2012 (300\%) al pasar de 139 mil hasta 567 mil dólares, además también es explicado por una disminución de las ventas totales de bienes, lo que generó que las exportaciones relativas de cebolla, expresado en el numerador de la fórmula que se observó en la Figura 1, sea mayor que el denominador expresado en exportaciones de competidores de referencia.

Tabla 5 Resultados obtenidos de VCR en las exportaciones de cebolla (2006-2019).

\begin{tabular}{rrrrrr}
\hline Año & Honduras & El Salvador & Guatemala & Costa Rica & Nicaragua \\
\hline 2006 & 0.15316282 & 0 & 3.73800792 & 0.28628384 & 3.29791597 \\
2007 & 0.22330329 & 0 & 2.85211553 & 0.22602677 & 1.00402403 \\
2008 & 0.29903627 & 0 & 2.99088271 & 0.03360885 & 1.32814484 \\
2009 & 0.35072178 & 0.00083787 & 2.68180315 & 0.04838931 & 2.31600532 \\
2010 & 0.58855051 & 0 & 2.43125529 & 0.01167947 & 2.41089747 \\
2011 & 0.74626342 & 0.00288264 & 2.24831452 & 0.02095643 & 2.5403387 \\
2012 & 0.22826439 & 0.00144444 & 3.18782357 & 0.03632954 & 0.48299125 \\
2013 & 1.00855735 & 0.00753589 & 3.08268707 & 0.04471544 & 0.00754453 \\
2014 & 0.37979179 & 0.00124908 & 3.11197519 & 0.10122684 & 0.03861242 \\
2015 & 0.76288638 & 0.00568714 & 2.70282055 & 0.01750868 & 0.30036757 \\
2016 & 0.11179081 & 0.00394814 & 3.08846923 & 0.01775702 & 0.05870564 \\
2017 & 0.58873671 & 0.00524145 & 2.83799899 & 0.01856076 & 0.36579557 \\
2018 & 0.31022899 & 0 & 2.77754214 & 0.12747233 & 0.65059699 \\
2019 & 0.22481387 & 0 & 2.80366298 & 0.0719769 & 0.55084407 \\
\hline
\end{tabular}


Como se puede observar en los resultados de la Tabla 5, tres países de la región no muestran ventaja comparativa en las exportaciones de cebolla enviadas al mundo, incluyendo a Honduras. Sin embargo, Guatemala tiene el valor promedio más alto, mostrando ventaja comparativa moderada mayor que 2 en todos los años analizados, eso es suficiente para afirmar que sus exportaciones tienen mayor desempeño en el comercio mundial comparado con sus competidores centroamericanos, de hecho, uno de los principales determinantes para que Guatemala sea el más competitivo de la región, es que dicho país representa el 84\% del total de exportaciones de cebolla en Centroamérica, el resto de países competidores registraron pocos ingresos, con un promedio de 5,783 dólares. Por otro lado, Nicaragua es el segundo país que muestra ventaja comparativa, aunque débil, con un valor promedio de VCR alrededor de 1.1.

Figura 6 Comportamiento de VCR en las exportaciones centroamericanas de cebolla hacia el mundo.

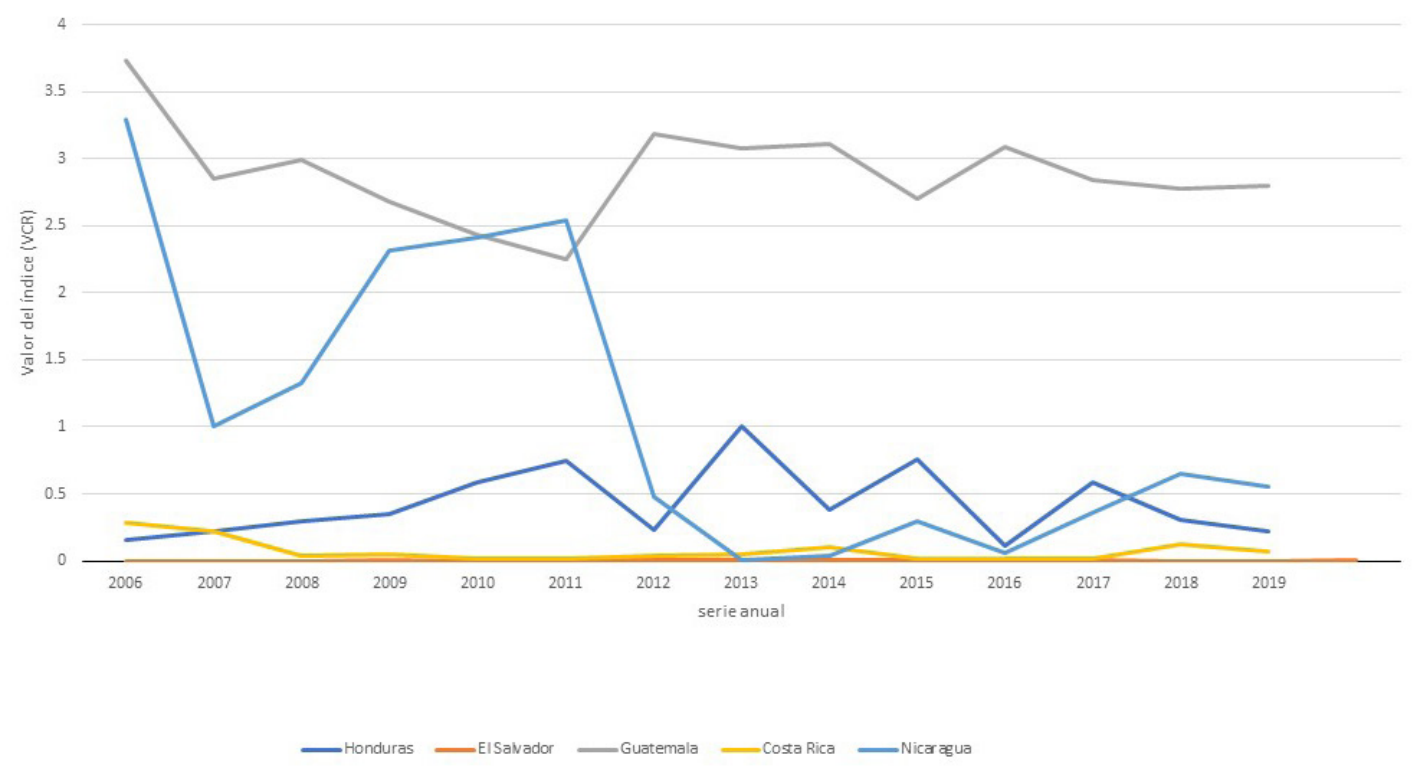

Fuente: Elaboración propia con datos de Trade Map

Como se puede observar en la Figura 6, Honduras, Costa Rica y E1 Salvador muestran los resultados más bajos de VCR menor que 1, lo que significa que no poseen ventaja comparativa en el mercado de la cebolla, explicado principalmente por un pequeño monto de exportaciones enviadas al mundo, especialmente desde El Salvador, que solamente realizó exportaciones de cebolla en seis de los años estudiados incluyendo los dos últimos; esto tiene como resultado un registro promedio de VCR igual a 0.0021 como el más bajo en la región.

Es interesante observar el comportamiento de VCR de Nicaragua, que, pese a mostrar un alentador resultado entre los años 2008-2010, sus exportaciones disminuyeron considerablemente. Este fenómeno es el principal factor por el cual los países de la región muestran baja competitividad.

Por otro lado, los resultados para Guatemala son respaldados por la (SAG, 2014b) en su informe sobre el mercado de la cebolla, en el cual se evidencia a ese país como el principal exportador de cebolla de la región, dicho esto, los principales destinos de sus exportaciones son: E1 Salvador, Nicaragua y Honduras, de hecho, E1 Salvador es el mayor importador de cebolla en Centroamérica y lo posiciona como el país con los registros más bajos del índice de VCR. 
En vista de los resultados mostrados en la presente investigación, se puede corroborar que Honduras sigue siendo un país que históricamente mantiene un volumen de exportaciones similar en todos los años analizados, principalmente de los productos primarios (agrícolas), esto toma una especial relevancia ya que el análisis de competitividad mide las exportaciones de cacao, miel natural y cebolla.

Aunado a lo anterior, los resultados de la VCR revelan que Honduras no cuenta con ventaja comparativa en ninguno de los productos estudiados y, además, sugieren que en la medida que las exportaciones de estos productos no crezcan significativamente, no se logrará la competitividad deseada para ser líderes en exportaciones para la región. Sin embargo, cabe señalar que no es suficiente con registrar más volumen exportado en valores absolutos, ya que el resto de los países centroamericanos verán aumentar sus exportaciones en la medida que, Honduras mantenga los niveles de importación proveniente del MCCA. En ese sentido, la clave para lograr competitividad es la especialización; lo que implica un menor costo relativo de producir y exportar un determinado producto comparado con los competidores y así, tener la capacidad de abastecer por completo el mercado local y luego competir en el exterior.

A continuación, en la Tabla 6, se muestran los resultados de VCR obtenidos para Honduras, con sus respectivos valores promedio.

Tabla 6 Resultados obtenidos de VCR para Honduras (2006-2019).

\begin{tabular}{cccc}
\hline Año & Cacao y sus preparaciones & Miel Natural & Cebolla (incluso chalotes) \\
\hline 2006 & 1.670317693 & 0.010123399 & 0.153162823 \\
2007 & 1.099237187 & 0.00844852 & 0.223303293 \\
2008 & 0.784239605 & 0.00509752 & 0.299036271 \\
2009 & 0.186977277 & 0.011116653 & 0.350721779 \\
2010 & 0.105394532 & 0 & 0.588550508 \\
2011 & 0.216248843 & 0.00318208 & 0.746263424 \\
2012 & 0.115823782 & 0.000611477 & 0.228264394 \\
2013 & 0.155071589 & 0.001142972 & 1.008557354 \\
2014 & 0.289702049 & 0 & 0.379791788 \\
2015 & 0.367596308 & 0 & 0.762886382 \\
2016 & 0.37484069 & 0.000817984 & 0.111790807 \\
2017 & 0.444493942 & 0.001856277 & 0.588736715 \\
2018 & 0.486470839 & 0.001853609 & 0.310228992 \\
2019 & 0.80174676 & 0.001397156 & 0.224813872 \\
\hline Promedio & 0.5070 & 0.0033 & 0.4269 \\
\hline
\end{tabular}

En vista de lo anterior, se puede observar que en valores promedio, Honduras no posee ventaja comparativa. El producto que más cerca estuvo de alcanzar valores competitivos es el cacao. Es importante destacar que Nicaragua posee el promedio de VCR más alto para el mercado de cacao (1.4969); en el caso del mercado de la miel natural, El Salvador cuenta con el índice promedio más alto con valor de 2.5252 y; para el mercado de cebolla es Guatemala, registrando un promedio de 2.8954 . 


\section{Conclusiones}

Honduras no muestra ventaja comparativa en las exportaciones de cebolla enviadas al mundo, sin embargo, evidencia un comportamiento volátil del índice al mostrar el valor más alto de la VCR= 0.74 en el año 2011 y luego mostrar un descenso sostenido hasta el punto de mostrar un valor de VCR muy cercano a cero. Para el mercado de miel natural, Honduras refleja un valor de VCR menor que 1 en todos los años objeto de estudio, de hecho, alcanza el nivel más bajo $(\mathrm{VCR}=0)$ en los años 2010, 2014 y 2015; comportamiento atribuido a que Honduras no registró exportaciones, lo que incrementó las importaciones. Para el mercado de cacao, las exportaciones registradas son mucho menores al valor registrado por el resto de los países de la región, evidenciando la baja competitividad comparado con los socios comerciales centroamericanos, dicho de otro modo, el resto de los países del MCCA son más especializados.

Honduras no posee ventaja comparativa en las exportaciones de ninguno de los productos analizados, esto tiene especial interés, ya que se debe priorizar la especialización en la producción de aquellos productos en los que el país tenga una dotación factorial abundante, en este caso, el factor tierra para los cultivos y cosechas. Sin embargo, se puede esperar que existan otros factores que determinen la baja competitividad en este producto.

Los datos de la VCR demuestran que los países que incrementan las exportaciones de productos y que disminuyen las importaciones, son más competitivos ya que logran abastecer su mercado local y tienen excedentes para exportar. Sin embargo, estas decisiones de política pública deben estar fundamentadas en los factores que determinan el volumen de exportaciones, como ser: la capacidad de producción de cada país, los salarios de la mano de obra, el mercado interno, sus prioridades comerciales y las condiciones climáticas para la producción, cosecha de productos agrícolas, los tratados comerciales y la calidad del producto. Estos factores, en el mejor de los casos, se traducen en un incremento de las exportaciones, la principal variable para mantener un valor de VCR mayor que 1.

Existe una fuerte relación entre la capacidad productiva y los niveles de competitividad de los países. Los resultados demostraron que Guatemala posee el mejor resultado del índice respecto a la cebolla, aunque no muestra ventaja comparativa y, además, es el mayor productor de cebolla de la región, sin embargo, esto solo demuestra que Guatemala no depende de las importaciones de cebolla ya que tiene una estructura productiva más eficiente que el resto de países de la región para lograr abastecer su mercado interno.

El resultado de VCR para el mercado centroamericano fue diseñado únicamente para medir ventajas comparativas entre los países miembros de la región, cabe destacar que los resultados mostrados en dicho índice no implican que los países tengan el mismo comportamiento en comparación con otros mercados (por ejemplo, zona EURO, América Latina y El Caribe) ya que los volúmenes de exportación y los precios de los productos agrícolas pueden variar según los acuerdos comerciales alcanzados con otro grupo de países.

Es interesante que ninguno de los países del MCCA mostró, en promedio, una fuerte ventaja comparativa $(\mathrm{VCR}>4)$ en ninguno de los productos agrícolas seleccionados. Sin embargo, llama la atención que Nicaragua es el único país de la región que en promedio mostró una Ventaja comparativa, aunque débil, en la exportación de los tres productos seleccionados. Por otro lado, demuestra que no existe un gran mercado de exportación mundial de cacao, cebolla y miel para los países centroamericanos. 
En respuesta a la primera hipótesis planteada, se concluye que, Honduras no posee ventaja comparativa en las exportaciones de cacao y sus preparaciones medido a través del índice de VCR respecto a los socios comerciales del MCCA.

En respuesta a la segunda hipótesis planteada, se concluye que Honduras no posee ventaja comparativa en las exportaciones de miel natural medido a través del índice de VCR respecto a los socios comerciales del MCCA.

En respuesta a la tercera hipótesis planteada, se concluye que, Honduras no posee ventaja comparativa en las exportaciones de cebolla medido a través del índice de VCR respecto a los socios comerciales del MCCA.

\section{REFERENCIAS}

Arias, J. y Segura, O. (2004). Índice de ventaja comparativa relevada: un indicador del desempeño y de la competitividad productivo-comercial de un país. https://www.researchgate.net/publication/272167573_Indice_de_ventaja_ comparativa_revelada_un_indicador_del_desempeno_y_de_la_competitividad_productivo-comercial_de_un_pais

Akhtar, W., Akmal, N., et al. (2013). Export competitiveness of pakistani horticultural products. $\quad$ P a $\mathrm{k}$ i s t a $\mathrm{n}$ J. Agric. Res. Vol. 26 No. 2. https://www.researchgate.net/profile/Hassnain_Shah/publication/264384970_ EXPOR T_COMPETITIVENESS_OF_PAKISTANI_HORTICULTURAL_PRODUCTS/links 53db23a70cf2a19eee8b46e0.pdf

Banco Central de Honduras (2019a). Informe de Comercio Exterior de Mercancías Generales. https:/www.bch.hn/ informe_comex.php

Banco Central de Honduras (2019b). Producto Interno Bruto Base 2000. https://www.bch.hn/pib_base2000.php

Banco Central de Honduras (2019c). Sistema Integrado de Comercio Exterior (SICE). https://see.bch.hn/SICE/ConsultaSACAjustado.aspx

Calmon, R. L., Droguett, R., da Silva, A., de Moura, M., Lisboa, G. J., y Midlej, M. (2020). Especialización y competitividad: análisis de las exportaciones brasileñas de cacao en grano y productos. Revista Dialnet. 11 (6), 12071219. https://dialnet.unirioja.es/servlet/articulo?codigo $=7575834$

Durán, J., y Alvarez, N. (2008). Indicadores de comercio exterior y política Comercial: mediciones de posición y dinamismo comercial. Santiago Chile: Naciones Unidas. Recuperado de https://www.cepal.org/es/publicaciones/3690indicadores-comercio-exterior-politica-comercial

Garzón, N. (2013). Análisis de la productividad, competitividad y estrategias de posicionamiento del cacao ecuatoriano en el mercado externo 2000-2010. http://repositorio.puce.edu.ec/handle/22000/6872

Gonzáles, R. (2017). Competitividad de las Exportaciones: Un análisis teórico deIndicadores de Ventajas Comparativas Reveladas y su aplicación a los datos de comercio de Paraguay. https://www.economia.gov.py/application/ files/3614/8949/6911/Documento_de_Trabajo_N1_-Competitividad_de_las_Exportaciones_Agricolas-14_ marzo_2017.pdf

Guerrero, D. (1995). La técnica, los costes la ventaja absoluta y la competitividad. https:/www.researchgate.net/ profile/Diego-Guerrero-6/publication/315642401_LA_TECNICA_LOS_COSTES_la_ventaja_absoluta_y_ la_competitividad/links/58d6bb7a92851c44d47fd814/LA-TECNICA-LOS-COSTES-la-ventaja-absoluta-y-lacompetitividad.pdf

Jaramillo, D. M. (2017). La especialización de la producción como estrategia competitiva para los productores de café y cacao. http://repositorio.utmachala.edu.ec/handle/48000/11287

Krugman, P. R., Obstfeld, M. y Melitz, M. J. (2012) Economía internacional: Teoría y política (9^a ed.). Madrid: Pearson Educación.

Lun-giao, M. (2009). International Comparison of the Export Competitiveness of Chinese Honey. Asian Agricultural 
Research, 01 (07), p. 17-20. https://ageconsearch.umn.edu/record/54029/

Magaña, M. A., Sanginés, J. R., Lara, P. E., Salazar, L. y Leiva, C. E. (2017). Competitividad y participación de la miel mexicana en el mercado mundial. Revista Mexicana de Ciencias Pecuarias. 8 (1), 4-52. https://doi.org/10.22319/ rmcp.v8i1.4304

Málaga, J. E., y Williams, G. W. (2010). La competitividad de México en la exportación de productos agrícolas. Revista Mexicana de Agronegocios. 27, 295-309. https://www.redalyc.org/articulo.oa?id=14114743002

Oliveros, D., y Pérez, S. (2013). Medición de la competitividad de los productores de Cacao en una región de Santander - Colombia. Revista Lebret (5). Colombia: Universidad Santo Tomás, p. 243-267. Recuperado de https://ialnet. unirioja.es/descarga/articulo/5983196.pdf

Olvera, J. D. (2018). Ventaja comparativa relevada del sector apícola de México en el comercio internacional de miel, periodo 2000-2016. México. http://bibliotecavirtual.dgb.umich.mx:8083/xmlui/bitstream/handle/DGB_ UMICH/1081/ININEE-M-2018-1856.pdf?sequence=1\&isAllowed=y

Pimentel, L. G. (2014). La igualación de los precios de los factores en el modelo Hecksher- Ohlin y la migración: un estudio comparativo de Estados Unidos y México. 9 (28), 40-54. http://tiempoeconomico.azc.uam.mx/wp-content/ uploads/2018/12/28te3.pdf

Pellandra, A., y Fuentes, J. (2011). El estado actual de la integración centroamericana: series de la CEPAL, estudios y perspectivas. (129). México: CEPAL. https://repositorio.cepal.org/handle/11362/4912

Rifin, A. (2013). Competitiveness of Indonesia's Cocoa Beans Export in the World Market. International Journal of Trade, Economics and Finance, Vol. 4, No. 5. Recuperado de https://pdfs.semanticscholar.org/836f/ aee08d5b610aca8fe3eb2e100433643eaaf2.pdf

Rodríguez, B. (Ed.). (1994). Adam Smith: La riqueza de las naciones. (1a ed., pp. 7-23.). Alianza Editorial. Recuperado de https://www.alianzaeditorial.es/primer_capitulo/la-riqueza-de-las-naciones.pdf

Sandoval, K., y Zetina, A. (2016). La cebolla mexicana: un análisis de competitividad en el mercado estadounidense, 20022013. No.70. Recuperado de http://www.scielo.org.mx/scielo.php?pid=S1870-39252017000300133\&script=sci abstract\&tlng=en

Secretaría de Agricultura y Ganadería (2016). Análisis de Coyuntura del Cultivo de Miel de Abeja en Honduras. http:// sisem.sag.gob.hn/PSME/D15LMU.php?id=1137

Secretaría de Agricultura y Ganadería (2014a). Perfiles de Mercado del cacao y sus preparaciones. https://areas.sag.gob. hn/pronagro/perfiles-de-mercado-1549070989603x541869683669991400

Secretaría de Agricultura y Ganadería (2014b). Perfiles de Mercado de la cebolla. https://areas.sag.gob.hn/pronagro/ perfiles-de-mercado-1549070989603×541869683669991400

Trade Map (2020). Lista de los mercados importadores para un producto exportado por Honduras Producto: 07 Hortalizas, plantas, raíces y tubérculos alimenticios. https://www.trademap.org/Country_SelProductCountry_ TS.aspx?nvpm=3\%7c340\%7c\%7c\%7c\%7c07\%7c\%7c\%7c2\%7c1\%7c1\%7c2\%7c2\%7c1\%7c2\%7c1\%7c1\%7c1

Vargas, H. (2014). Desempeño competitivo de productos agropecuarios de Guatemala: una evaluación con base en las ventajas por el comercio internacional de 2000 a 2010. Editorial Kamar. Costa Rica. http://repositorio.iica.int/ bitstream/handle/11324/11406/BVE20088036e.pdf?sequence=1\&isAllowed=y

Villarreal, F. J., Guerrero, J. I., de la Cruz, J. J. y Ayala, M. L. (2020). El teorema de heckscher y ohlin y la industria mexicana de las nueces de nogal (carya illinoinensis). Revista Mexicana de Agronegocios. 46, 406-421. https:// ageconsearch.umn.edu/record/303882/ 


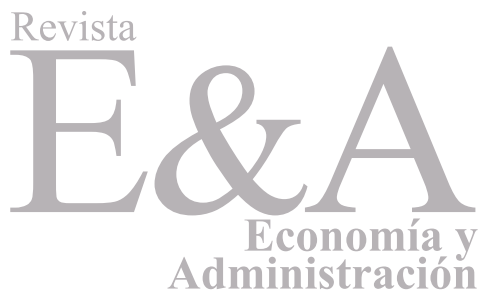

